\title{
Optimization of Multiple Input Process Parameters of WEDM on Titanium Ti 6Al-4v (Grade 5) By Taguchi Analysis
}

\section{A.G.Karthikeyan ${ }^{1}$, V.P.Pradeep ${ }^{2}$, M.Maruthapandian ${ }^{3}$}

${ }^{1,2}$ Assistant Professor, Department of Mechanical Engineering, Dr.N.G.P. Institute of Technology, Coimbatore-641048, Tamilnadu, India.

${ }^{3}$ Assistant Professor, Department of Automobile Engineering, The Kavery College of Engineering, Salem636453, Tamilnadu, India.

\begin{abstract}
The experimental study is about the optimizing the cutting process parameters of the WEDM (Wirecut Electric Discharge Machining) during the machining of Titanium Ti 6Al-4V (Grade 5) material. The high strength and high hardness of Titanium Ti 6Al-4V (Grade 5) alloy offers a challenging task in obtaining a better surface finish and Material Removal Rate. The material removal rate and the surface roughness of Titanium Ti 6Al-4V (Grade 5) is carried out and an excellent machined surface can be obtained by the setting the machining parameters at optimum level by various experimental study of material while machining in WEDM. The machining parameters such as Pulse ON time (TON), Pulse OFF time (TOFF), Gap Voltage (GV) and Wire Feed Rate (WFR) used as input parameters to attain optimum output responses like Material Removal Rate(MRR) and surface roughness using Taguchi's DOE approach. In this present work, 9 Experiments were conducted for 4 inputs Parameter and 3 levels for each Input parameter and the experimental results of MRR were analysed using Taguchi method. From the Signal to Noise ratio values of MRR, the optimum levels of selected Input Process Parameter were found successfully. Key words: Ti 6Al-4v, WEDM, MRR, SR, CS
\end{abstract}

\section{Introduction}

Accompanying the development of aerospace materials, the demands for alloy materials having high hardness, toughness and impact resistance are increasing. Nevertheless, such materials are difficult to be machined by old-style machining methods. Hence, WEDM process with a tinny brass wire as an electrode transformed as thermal energy from electrical energy for cutting materials. High hardness and toughness materials such as conductive ceramics, alloy steels and aerospace materials can be machined. Additionally, WEDM is capable of producing a corrosion and wear resistant surface.
WEDM is considered as a exclusive implementation of the conventional EDM process, which uses an conductor to set the sparking process. However, WEDM utilizes a continuously travelling wire electrode made of thin brass wire of diameter 0.25 $\mathrm{mm}$, which is capable of attaining very small corner radii. In this experiment $0.30 \mathrm{~mm}$ brass wire is used for machining operation. The wire is kept in tension using a mechanical tensioning device reducing the tendency of producing inaccurate parts. During the WEDM process, the material is eroded ahead of the wire and there is no direct contact between the work piece and the wire, eliminating the mechanical stresses during machining. 


\section{www.rspsciencehub.com}

Goswami Amitesh et.al (2012) work investigates the influence of machining parameters on MRR for machining of superalloy Nimonic 80A with brass wire as tool electrode. Material removal rate (MRR) decreases with increase in Toff and gap voltage set whereas MRR increases with increase in Ton and peak current (IP). While machining of nimonic alloys, there is shear in the chip which produces abrasive toothed edges. Also, high strength is maintained at elevated temperatures, which compete against the plastic deformation.

Shajan Kuriakose et.al (2004) reveals that WEDM broadly used for machining a variety of hardest materials including titanium alloys with complicated shapes. Parameters like time between (TB) pulses, wire tension and dielectric pressure influenced on the surface characteristics. When the TB is longer, the number of discharges within a given period of time becomes less, leading to non-uniform cooling and heating. Large pulse duration (TA) leads to greater electrical discharging energy, which will generate more heat energy. In order to obtain better surface characteristics, the coated wires are preferred. Time between two pulses is the most delicate parameter that impacts the formation of oxides layers. When lower the time between pulses maintained a considerable reduction in the formation of oxides.

Aniza Aliasa et.al (2012) observed that the influence of three different machine rates with constant current with WEDM of Titanium Ti-6Al$4 \mathrm{~V}$. In this work, it was made to determine the significant machining factors for the performance of WEDM viz. Material Removal Rate, Surface Roughness and Kerf Width. Machine feed rate have been proven to play an important role in this experimental work. Since the low kerf and the high MRR are equally important goals in WEDM, equal machine feed rate are recommended. The MRR decreased with the minimum feed rate. MRR was found as open circuit voltage and pulse duration, whereas wire speed rate and dielectric pressure were less operational factors. The increase of voltage means that the electric field becomes stronger and the spark discharge takes place more easily under the same gap and a coarse surface is always obtained. WEDM can be used to improved surface roughness of titanium (Ti-6Al-4V) work piece.
Volume 02 Issue 06 June 2020

Vamsi Krishna pasam et.al (2004) is widely used in machining of materials when accuracy is of major factors. Selection of optimal machining parameters combinations for attaining higher accuracy is a stimulating task in WEDM due to the presence of a large number of process parameters. In the present work, titanium alloy is machined in WEDM by optimum setting of parameters through taguchi design. Also, developed mathematical model to predict responses through by Genetic Algorithm.

Neeraj Sharma et.al (2010) work investigated cryogenic treated high carbon high chromium alloy cold tool steels (D-3) are used in production of high performance punching tools. In this work, the effects of various control factors of WEDM have been investigated for optimizing surface roughness while machining cryogenic treated D-3 material. Signal toNoise (S/N) ratio, Analysis of Variance (ANOVA) and various plots were used for optimum process parameters for fine surface finish.

Rohit Garg (2010) accompanying the development of mechanical industry, the demands for alloy materials having high hardness, toughness and impact resistance are increasing. Wire EDM machines are used to cut conductive metals of any hardness or that are difficult or impossible to cut with traditional methods. The machines also specialize in cutting complex contours or fragile geometries that would be difficult to be produced using conventional cutting methods. There is better visualization of the responses due to 3-D graphs in RSM, where as there is no such representation of the responses through Taguchi's approach. Moreover, it is possible to obtain regression equations correlating the dependent response with the independent variables through RSM which is not possible through Taguchi's technique. Aditya Modgil (2003) investigated that high speed machining of MTRC on Ti6Al4V alloy work-piece resulted in good surface integrity. Also, metallographic study produced fatigue cracks leads to lower fatigue life. The better optimum process parameter leads to better surface finish and fine grains. Liao et.al (2009) successfully developed an on-line analysis system for investigating the causality of the Td in the WEDM process. In terms of the algorithms adopted in the system, the autocorrelation function is able to detect 


\section{www.rspsciencehub.com}

the consecutive arc or short circuit discharges. Although the experiments conducted in the study showed that several factors were able to induce periodically repeated patterns in $\mathrm{Td}$ data sequence, it still too early to conclude that a certain component appearing in the $\mathrm{Td}$ spectrum can be exclusively attributed to any unique factor. Since the factors influencing the Td spectrum may confound with each other among themselves, a more scrutinized and thorough research has to be designed and conducted in order to establish the models for system identification, and it is underway. Koshy et.al (2008) Successful operation of the WEDM process depends on the appropriate choice of the electrical parameters and the abrasive wire that would facilitate material removal by both spark erosion and abrasion. Initial AWEDM experiments indicated the range of electrical parameters that could be effectively employed with the abrasive wire to be severely limited by wire failure. Detailed examination of the cross-section of failed wires attributed this to process-induced embrittlement of the steel core, with its hardness having increased from 54 HRC to 64 HRC, which approaches the maximum hardness for steel. Mohd Ahadlin Mohd Daud et.al (2004) observed that proper maintaining of peak current, Gap voltage, pulse on time and pulse off time levels on WEDM leads to small cutting pits and crater size in work-piece. Also, average surface roughness was maximum for polished specimen after machined on WEDM. When peak current, gap voltage and Ton are maximum, cutting pits and cracks are larger and vice-versa.[1-4] Muthu Kumar et.al (2010) reported an application of both Taguchi and Grey Relational Taguchi Analysis, to improve the multiresponse characteristics on Material Removal Rate, Surface roughness in WEDM of super-alloy Incoloy 800. As a result, this method greatly streamlines the optimization of complex multiple performance characteristics. Olofson et.al (1965) Metallographic examination showed that the electrolytically ground surfaces were satisfactory (i.e., uniform in appearance, free of pits, intergranular attack, etc.) The term electrolytic grinding (EG) as used in this report refers to metal removal by a combination of electrochemical action and mechanical abrasion. Electrolytic grinding might be considered as a specialized form of electrochemical machining.
Volume 02 Issue 06 June 2020

Electrolyte formulations aim at providing good conductivity, good grinding performance, and also at being nontoxic and noncorrosive to personnel, machines, and surroundings. Sarkar et.al (2008) investigated that Ti-Al alloy on WEDM has been carried out to produce desired geometrical accuracy and surface finish. Tremendous potential energy of WEDM gives good surface finish and precision machining quality. Mathematical model developed to predict output responses by optimum setting of process parameters. Scott F. Miller et.al (2004) investigated that voltage spark cycle effects and pulse on-time on WDM of metal foams, metal bond grinding wheels, sintered Nd-Fe-B magnet and carbon-carbon bipolar plate. Regression model was applied to MRR and SEM analysis was used to investigate effect of better surface finish. This study also confirmed the ability of WEDM process to machine different advanced smart materials. Above advanced smart materials are difficult to machine in conventional method whereas better surface finish and higher MRR rate obtained in advanced WEDM machining method. Singh et.al (2009) concluded that wire feed rate and wire tension process parameters of WEDM have no effect on the material removal rate. Also by increasing the pulse on time and peak current the material removal rate increased. When the pulse off time and servo voltage increased the material removal rate decreased. The material removal rate directly increases with increase in pulse on time and peak current while decreases with increase in pulse off time and servo voltage.[5-8] From the literature survey it is understood very limited work has been reported on optimization of process variables. The effect of machining parameters on Titanium ( $\mathrm{Ti} 6 \mathrm{Al} 4 \mathrm{~V}$ ) has not been fully explored using WEDM with brass wire as electrode. Multi-response optimization of WEDM process is another thrust area which has been given less attention in past studies. In thi work "Effect of Process Parameters on Performance Measures of Wire Electrical Discharge Machining" has been undertaken keeping into consideration the following problems. It has been long recognized that cutting conditions such as pulse on time, pulse off time, servo voltage, peak current and other machining parameters should be selected to optimize the economics of machining operations as assessed by 
www.rspsciencehub.com

productivity, total manufacturing cost per component or another suitable criterion. [9-12] The work aims in optimizing the process parameters at the different working ranges by selecting one parameter at a time. Experimental determination about the effects of the various process parameters viz pulse on time, pulse off time, spark gap set voltage, peak current, wire feed and wire tension on the performance measures like cutting rate, surface roughness, gap current and dimensional deviation in WEDM process is to be enumerated. Taguchi method is deployed for the Optimization process. To improve the output responses such as MRR \& SR with respect to the input process parameters such as

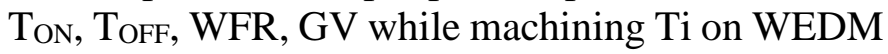
by Taguchi method.[13-15]

\section{Experimental Methodology}

In order to obtained high material removal rate and better surface quality produced by WEDM process, it is determined to optimum level of process parameters. Table 1 shows the WEDM selected controlled factors and its levels. The following controllable factors were selected for these studies as follows:
1. Pulse on Time (Ton)
2. Pulse off Time (Toff).
3. Wire feed rate (WFR)
4. Gap voltage $(\mathrm{GV})$

Table.1. Process Parameters \& levels

\begin{tabular}{|c|c|c|c|c|c|}
\hline $\begin{array}{c}\text { S. } \\
\text { No }\end{array}$ & $\begin{array}{c}\text { Process } \\
\text { Parameters }\end{array}$ & Units & $\begin{array}{c}\text { Level } \\
\mathbf{1}\end{array}$ & $\begin{array}{c}\text { Level } \\
\mathbf{2}\end{array}$ & $\begin{array}{c}\text { Level } \\
\mathbf{3}\end{array}$ \\
\hline 1 & $\mathrm{~T}_{\mathrm{ON}}(\mathrm{A})$ & $\mu \mathrm{s}$ & 6 & 7 & 8 \\
\hline 2 & $\mathrm{~T}_{\mathrm{OFF}}(\mathrm{B})$ & $\mu \mathrm{s}$ & 4 & 5 & 6 \\
\hline 3 & WFR (C) & $\mathrm{mm} / \mathrm{min}$ & 2 & 4 & 6 \\
\hline 4 & GV (D) & $\mathrm{V}$ & 40 & 50 & 60 \\
\hline
\end{tabular}

Volume 02 Issue 06 June 2020

In order to evaluate the effects of controllable factors or process parameters on performance characteristics (Ra, CS and MRR) and to ascertain the performance characteristics under the optimal machining parameters. In this study the Taguchi method, a special design procedure is applied.

Taguchi Procedure for Experimental design and Analysis

1. Selection of Orthogonal Array

2. Task of parameters and interactions to orthogonal Array

3. Data Analysis

4. Determination of Confidence Intervals

5. Confirmation Experiment.

\subsection{Taguchi's Design of Experiments}

In this work, the optimal setting of the process parameters obtained by Taguchi's DoE approach. Taguchi's L9 mixed type of Orthogonal array $(\mathrm{OA})$ is used to conducted the experiments. In L9 OA, four parameters having three level each. Present work have been investigate the effects of important parameters viz., Pulse on time, Pulse off time, Wire feed rate and Gap voltage on three output responses such as cutting speed, material removal rate and surface roughness.

\subsection{Taguchi Experiment}

This experiment has 4 variables at 3 different settings. A full factorial experiment would require $3^{2}$ $=9$ experiments. We conducted a Taguchi experiment with a L9 $\left(3^{2}\right)$ orthogonal array (9 tests, 2 variables, 3 levels) shown in Table 2.

\subsection{Material Removal Rate (MRR)}

Maximum Material Removal Rate is an important indicator of the efficiency and cost effectiveness of the WEDM process. However increasing MRR may scarify the surface integrity of the work-piece. Also MRR increases the poor surface finish. In WEDM, The material removal rate (MRR) can be obtained from the expression

Cutting Speed = Length of Wire Travel / Total Time Taken for Cutting (1)

MRR = Cutting Speed $x$ Height of WorkPiece 
www.rspsciencehub.com

Table.2. Taguchi experiment design

\begin{tabular}{|c|c|c|c|c|}
\hline Experiment & A & B & C & D \\
\hline 1 & A1 & B1 & C1 & D1 \\
\hline 2 & A1 & B2 & C2 & D2 \\
\hline 3 & A1 & B3 & C3 & D3 \\
\hline 4 & A2 & B1 & C2 & D3 \\
\hline 5 & A2 & B2 & C3 & D1 \\
\hline 6 & A2 & B3 & C1 & D2 \\
\hline 7 & A3 & B1 & C3 & D2 \\
\hline 8 & A3 & B2 & C2 & D3 \\
\hline 9 & A3 & B3 & C1 & D1 \\
\hline
\end{tabular}

\subsection{TITANIUM Ti 6Al-4V (Grade 5)}

It is accounted that 50 percentage of total titanium usage the world over. Titanium alloys Ti$6 \mathrm{Al}-4 \mathrm{~V}$ (Grade 5) may be heat treated to increases its strength. Therefore, this alloy offers its high strength with light weight and high corrosion resistance. Ti6AI-4V's usability makes the medical applications, marine, aerospace and chemical processing 3. Results and Discussions

The profile was cut using WEDM on the combinations of various parameters. The parameters and values are listed below in Table 5. Experiments have been carried out on the WEDM set up as showed, and the data were collected with
Volume 02 Issue 06 June 2020

industries. Table 3 and Table 4 shows that, titanium alloy chemical composition and mechanical properties.

Table.3. Titanium alloy chemical composition

\begin{tabular}{|c|c|}
\hline ELEMENTS & SPECIMEN WEIGHT \% \\
\hline $\mathrm{C}$ & 0.08 \\
\hline $\mathrm{Fe}$ & 0.25 \\
\hline $\mathrm{N}_{2}$ & 0.05 \\
\hline $\mathrm{O}_{2}$ & 0.2 \\
\hline $\mathrm{Al}$ & $5.5-6.76$ \\
\hline $\mathrm{V}$ & $3.5-4.5$ \\
\hline $\mathrm{Ti}$ & Balance \\
\hline
\end{tabular}

Table.4. Mechanical Properties of Titanium

\begin{tabular}{|c|c|}
\hline DESCRIPTION & COMPOSITION \\
\hline Hardness, Brinell & 334 \\
\hline Hardness, Knoop & 363 \\
\hline Hardness, Rockwell C & 36 \\
\hline Hardness, Vickers & 349 \\
\hline Tensile Strength, Yield & $880 \mathrm{Mpa}$ \\
\hline $\begin{array}{c}\text { Tensile Strength, } \\
\text { Ultimate }\end{array}$ & $950 \mathrm{Mpa}$ \\
\hline Modulus of Elasticity & $113.8 \mathrm{Gpa}$ \\
\hline Poisson's Ratio & 0.342 \\
\hline Fatigue Strength & $240 \mathrm{Mpa}$ \\
\hline Fracture Toughness & $75 \mathrm{pa}$ \\
\hline
\end{tabular}

respect to the influence of the predominant process parameters on MRR. The experiment was conducted at 9numbers of combinations for profile1 as per the conditions of run as depicted in the Table 5 respectively. 
Table 5 Different input parameter used in the experiment for profile

\begin{tabular}{|c|c|c|c|c|c|c|}
\hline S.NO & $\begin{array}{c}\text { PULSE ON } \\
\text { TIME } \\
\text { ToN } \\
(\boldsymbol{\mu s})\end{array}$ & $\begin{array}{c}\text { PULSE OFF } \\
\text { TIME } \\
\text { ToFF } \\
(\boldsymbol{\mu s})\end{array}$ & $\begin{array}{c}\text { WIRE } \\
\text { FEED } \\
\mathbf{m} / \mathbf{m i n}\end{array}$ & $\begin{array}{c}\text { SPARK GAP } \\
\text { SET VOLTAGE } \\
(\mathbf{V})\end{array}$ & $\begin{array}{c}\text { WIRE } \\
\text { TENSION } \\
(\mathbf{g})\end{array}$ & $\begin{array}{c}\text { PEAK } \\
\text { CURRENT } \\
\text { Amps }\end{array}$ \\
\hline 1 & 6 & 4 & 2 & 40 & 1300 & 1 \\
\hline 2 & 6 & 5 & 4 & 50 & 1300 & 1 \\
\hline 3 & 6 & 6 & 6 & 60 & 1300 & 1 \\
\hline 4 & 7 & 4 & 4 & 60 & 1300 & 1 \\
\hline 5 & 7 & 5 & 6 & 40 & 1300 & 1 \\
\hline 6 & 7 & 6 & 2 & 50 & 1300 & 1 \\
\hline 7 & 8 & 4 & 6 & 50 & 1300 & 1 \\
\hline 8 & 8 & 5 & 2 & 60 & 1300 & 1 \\
\hline 9 & 8 & 6 & 4 & 40 & 1300 & 1 \\
\hline
\end{tabular}

\subsection{Calculation of MRR}

Material Removal Rate for individual experiment was calculated using standard formula. The Fig. 1 illustrates the image for kerf width for profile -1 . Also, The Surface Roughness test was conducted for the profile 1-9. The obtained results for profile are as follows.

1. The total length of wire travel for profile-1 $=101 \mathrm{~mm}$

Time taken for each experiment was calculated by Odometer.

$$
\mathrm{CS}=\frac{\text { Length in mm }}{\text { Time taken in minutes }}
$$

MRR = CS $x$ Height of the Workpiece $\left(\mathrm{mm}^{2} /\right.$ minute $)$

From the Fig. 2 it is shown that a surface roughness of $R_{a} 1.103 \mu \mathrm{m}$ is measured for the profile - 1

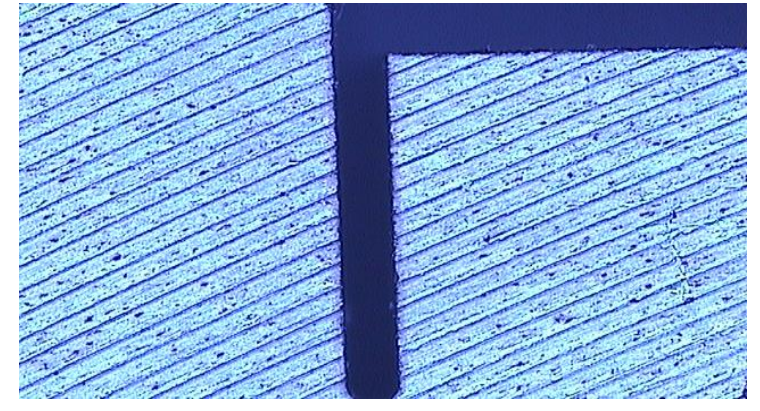

Fig.1. Kerf Width image for profile -1

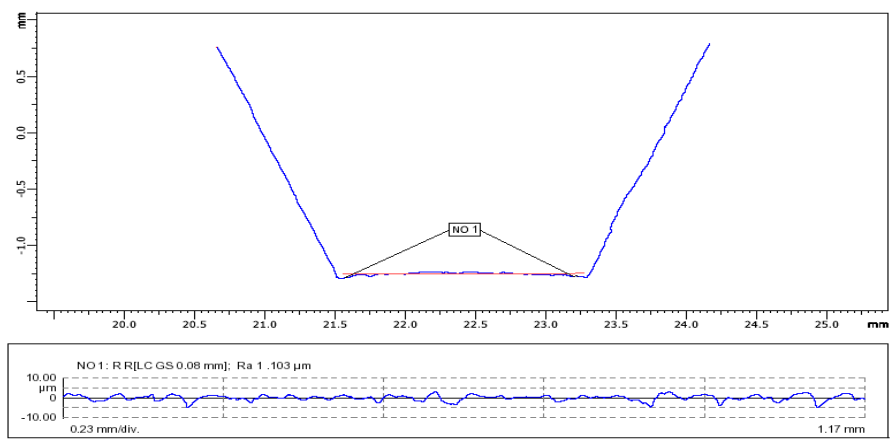

Fig.2. Surface Roughness measurement for profile -1 


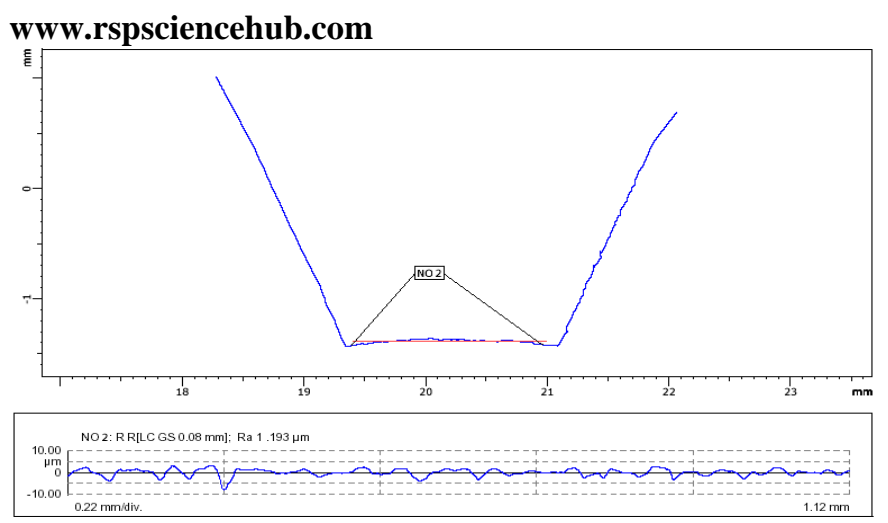

Fig.3. Surface Roughness measurement for profile -2

From the Fig. 3 it is shown that a surface roughness of $R_{a}=1.193 \mu \mathrm{m}$ is measured for the profile -2

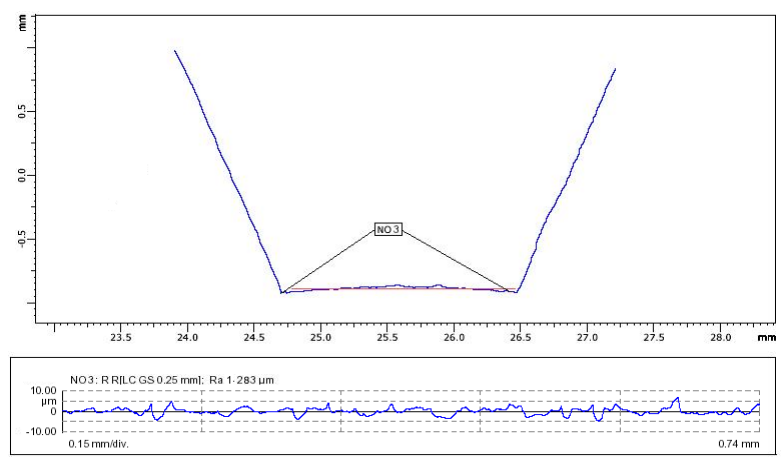

Fig.4. Surface Roughness measurement for profile $-\mathbf{3}$

From the Fig. 4 it is shown that a surface roughness of $\mathrm{Ra}=1.289 \mu \mathrm{m}$ is measured for the profile -3

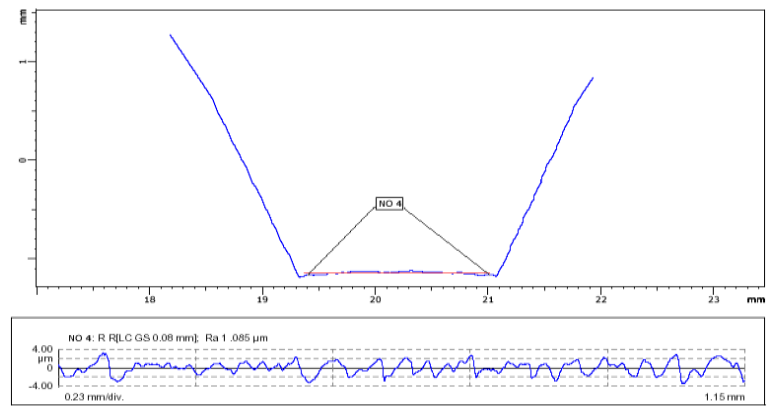

Fig.5. Surface Roughness measurement for

$$
\text { profile }-4
$$

From the Fig. 5 it is shown that a surface roughness of $\mathrm{Ra}=1.085 \mu \mathrm{m}$ is measured for the profile -4
Volume 02 Issue 06 June 2020

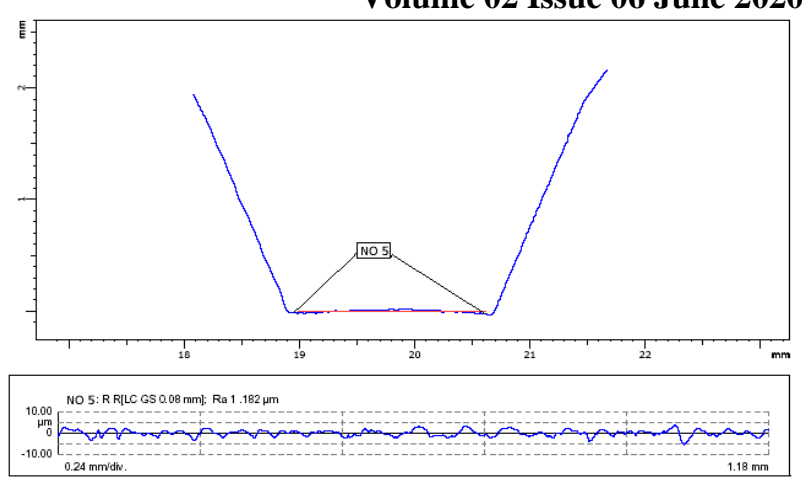

Fig.6. Surface Roughness measurement for profile -5

From the Fig. 6 it is shown that a surface roughness of $\mathrm{Ra}=1.182 \mu \mathrm{m}$ is measured for the profile -5

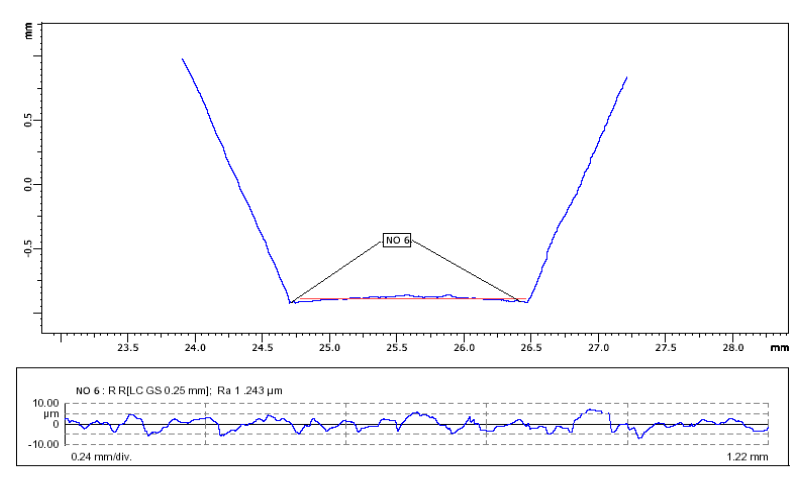

Fig.7. Surface Roughness measurement for

$$
\text { profile }-6
$$

From the Fig. 7 it is shown that a surface roughness of $\mathrm{Ra}=1.243 \mu \mathrm{m}$ is measured for the profile -6

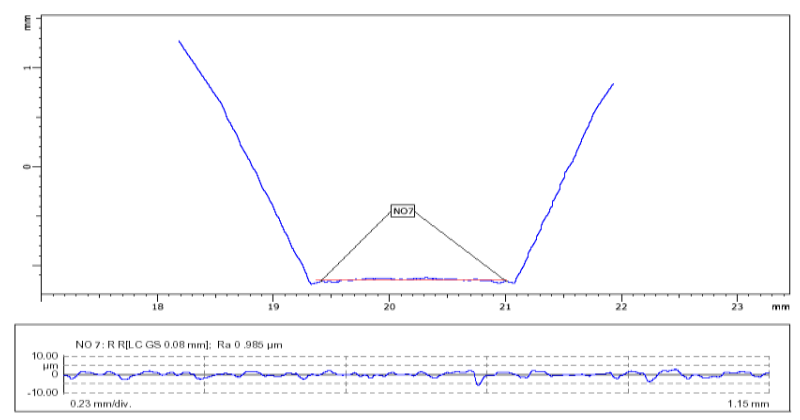

Fig.8. Surface Roughness measurement for

$$
\text { profile }-7
$$

From the Fig. 5.8 it is shown that a surface roughness of $\mathrm{Ra}=0.985 \mu \mathrm{m}$ is measured for the profile - 7 


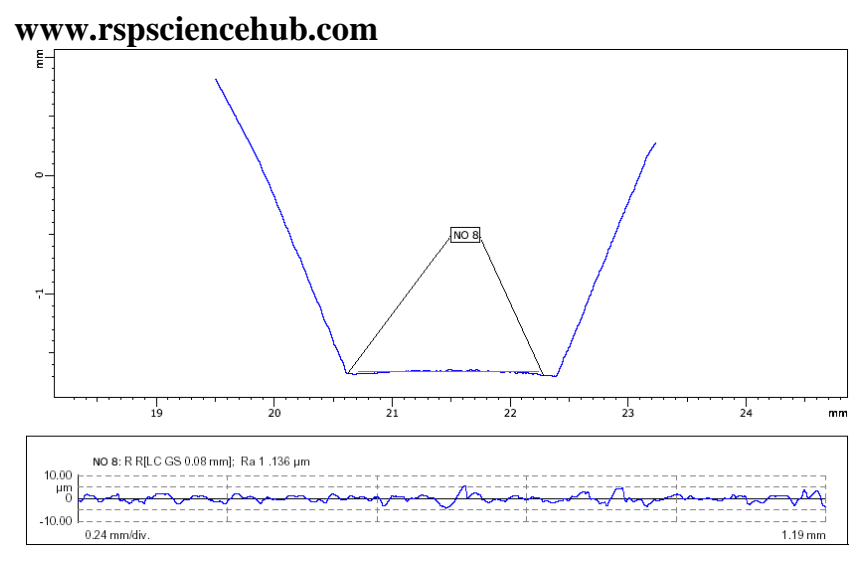

Fig.9. Surface Roughness measurement for profile -8

From the Fig. 9 it is shown that a surface roughness of $\mathrm{Ra}=1.136 \mu \mathrm{m}$ is measured for the profile -8

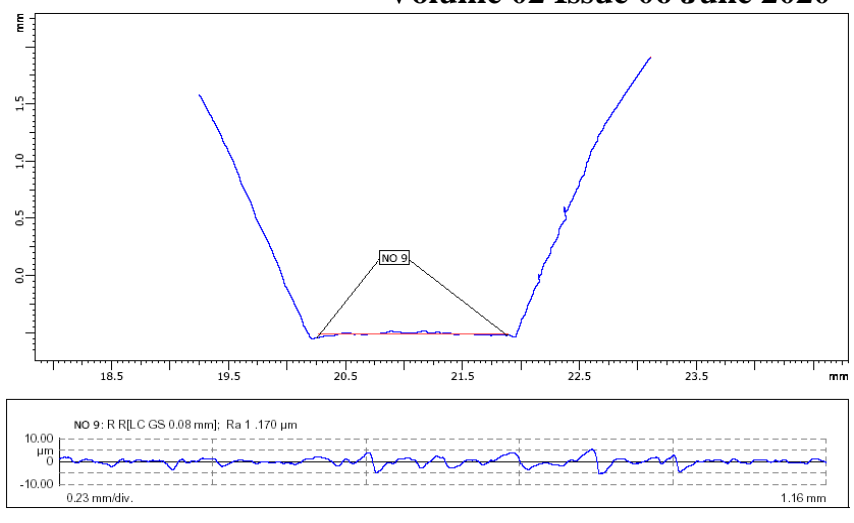

Fig10. Surface Roughness measurement for profile -9

From the Fig. 10 it is shown that a surface roughness of $\mathrm{Ra}=1.170 \mu \mathrm{m}$ is measured for the profile -9 . The cutting speed, Surface roughness and Material removal rate are presented in Table 6.

Table.6. Experimental results

\begin{tabular}{|c|c|c|c|c|c|c|c|}
\hline S.NO & $\begin{array}{c}\text { PULSE } \\
\text { ON TIME } \\
\text { ToN } \\
(\boldsymbol{\mu S})\end{array}$ & $\begin{array}{c}\text { PULSE } \\
\text { OFF TIME } \\
\text { ToFF } \\
(\boldsymbol{\mu s})\end{array}$ & $\begin{array}{c}\text { WIRE } \\
\text { FEED } \\
\mathbf{m m} / \mathbf{m i n}\end{array}$ & $\begin{array}{c}\text { SPARK GAP } \\
\text { SET VOLTAGE } \\
(\mathbf{V})\end{array}$ & $\begin{array}{c}\text { Cutting } \\
\text { Speed } \\
(\mathbf{m m} / \\
\mathbf{m i n})\end{array}$ & $\begin{array}{c}\text { MRR } \\
\left(\mathbf{m m}^{2} / \mathbf{m i n}\right)\end{array}$ & $\begin{array}{c}\text { Surface } \\
\text { Roughness } \\
(\boldsymbol{\mu m})\end{array}$ \\
\hline 1 & 6 & 4 & 2 & 40 & 3.26 & 5.86 & 1.103 \\
\hline 2 & 7 & 4 & 4 & 50 & 3.61 & 6.49 & 1.193 \\
\hline 3 & 8 & 4 & 6 & 60 & 4.04 & 7.27 & 1.283 \\
\hline 4 & 6 & 5 & 4 & 60 & 2.89 & 5.19 & 1.085 \\
\hline 5 & 7 & 5 & 6 & 40 & 2.97 & 5.35 & 1.182 \\
\hline 6 & 8 & 5 & 2 & 50 & 3.16 & 5.68 & 1.243 \\
\hline 7 & 6 & 6 & 6 & 50 & 2.59 & 4.66 & 0.985 \\
\hline 8 & 7 & 6 & 2 & 60 & 2.89 & 5.19 & 1.136 \\
\hline 9 & 8 & 6 & 4 & 40 & 2.97 & 5.35 & 1.170 \\
\hline
\end{tabular}

The Fig.11 shows that higher signal to noise ratio for higher MRR. At A1, B3, C3, D3 the signal to noise ratio is higher and MRR is optimal at the range. The Fig. 12 indicates that the non-linear $\mathrm{S} / \mathrm{N}$ ratios fitted on a linear probability plot having a pvalue of 0.380 
www.rspsciencehub.com

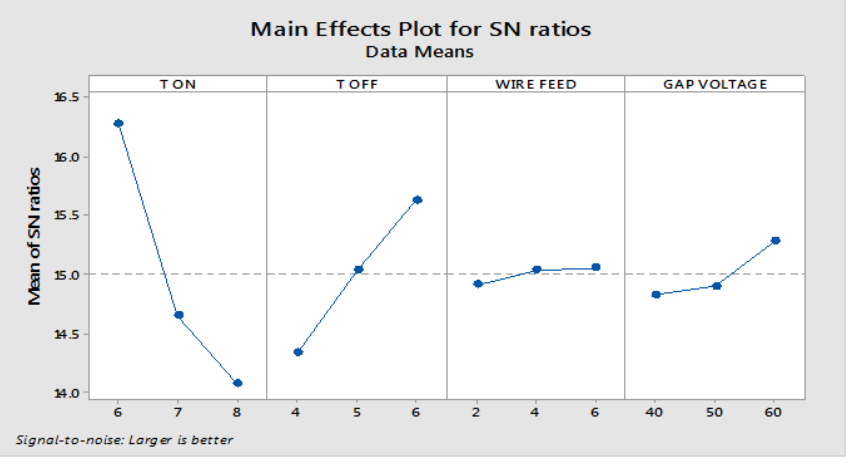

Fig.11. Main Effects Plot for S/N ratios of MRR

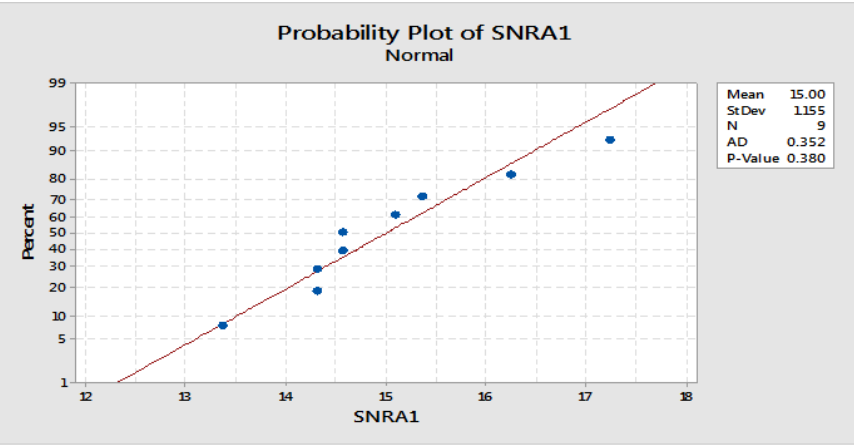

Fig.12. Normal probability plot for $\mathrm{S} / \mathrm{N}$ ratios of MRR

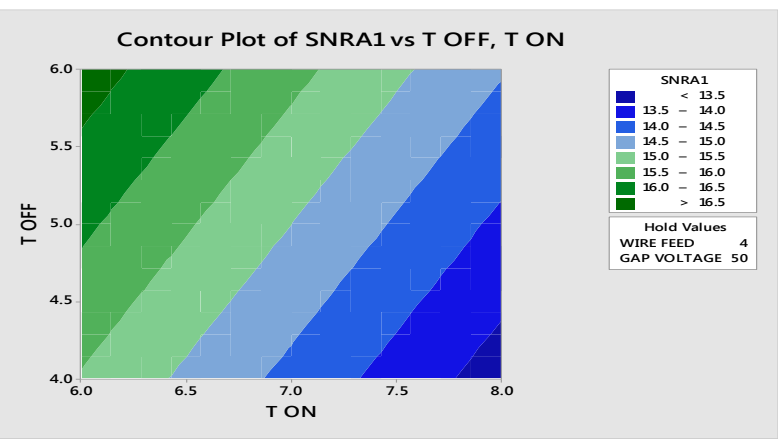

Fig.13. Contour plot for $\mathrm{S} / \mathrm{N}$ ratios of $\mathrm{MRR}$ vs Ton, ToFF

The Fig 13 illustrates a contour plot for $\mathrm{S} / \mathrm{N}$ ratio for MRR indicates that for higher $\mathrm{S} / \mathrm{N}$ ratio MRR is better. The greener region has the highest $\mathrm{S} / \mathrm{N}$ ratio and it results in better MRR. The Fig. 14 illustrates that for smaller signal to noise ratio the Surface Roughness is optimal. At A1, B1, C1, D3 the signal to noise ratio is smaller and Surface Roughness is optimal at the range. The results plotted above portrays that the cutting speed directly varies with MRR. For the first three trials, the Pulse off Time is maintained constant and the Pulse on Time is varied.
Volume 02 Issue 06 June 2020

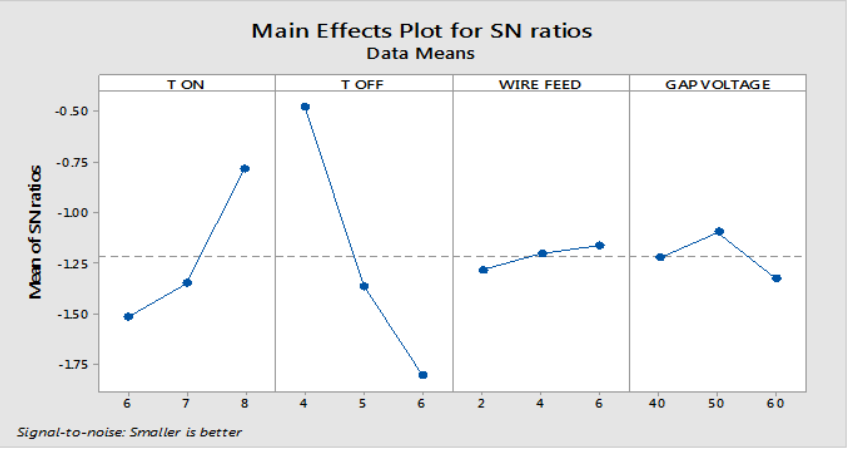

Fig.14. Main Effects Plot for S/N ratios of SR

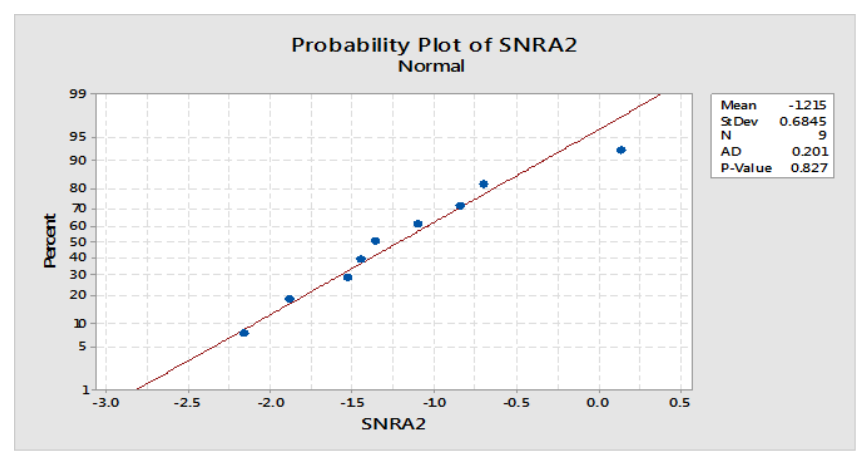

Fig.15. Normal probability plot for $\mathrm{S} / \mathrm{N}$ ratios of SR

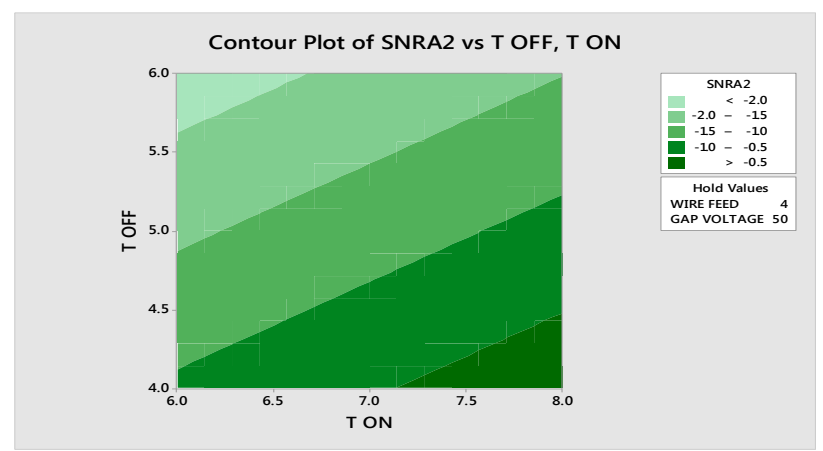

Fig.16. Contour plot for $\mathrm{S} / \mathrm{N}$ ratios of $\mathrm{SR}$ vs $\mathrm{T}_{\mathrm{ON}}$, ToFf

The maximum MRR of $7.27 \mathrm{~mm}^{2} / \mathrm{min}$ is obtained at Ton $=8 \mu \mathrm{s}$. on the second set of three trials, the pulse off time is slightly increased and it is visible from the table the MRR is decreased compared to the previous one. The same condition exists for the third set of trials also. The surface roughness directly varies with the cutting speed. For the high cutting speed, the surface roughness is measured as high value $1.597 \mu \mathrm{m}$ which corresponds to the high MRR. It is found that for high cutting speed $4.04 \mathrm{~mm} / \mathrm{min}$, high MRR $7.27 \mathrm{~mm}^{2} / \mathrm{min}$ is obtained. 


\section{www.rspsciencehub.com}

\section{Conclusions}

In this work, the effect of Wire EDM process parameters on Titanium $\mathrm{Ti} 6 \mathrm{Al} 4 \mathrm{~V}$ has been reported. The study of wire cut Electrical Discharge Machine (WEDM) for machining Titanium was done. Four process parameters with three levels have been selected. The high metal removal rate (MRR) for machined Titanium was calculated. The optimum parameters levels using the multicharacteristic optimization model has been validated by confirmation experiments. The optimal setting of process parameters are Ton $=8 \mu \mathrm{s}$, Toff $=$ $4 \mu \mathrm{s}, \quad \mathrm{WFR}=6 \quad \mathrm{~mm} / \mathrm{min}$ and $\mathrm{GV}=50 \mathrm{~V}$. Corresponding to this setting experimental value are $\mathrm{CS}=4.04 \mathrm{~mm} / \mathrm{min}, \quad$ MRR $=7.27 \mathrm{~mm}^{2} / \mathrm{min}$ and $\mathrm{SR}=0.985 \mu \mathrm{m}$. The characteristics Process Parameters in WEDM are Surface roughness, cutting speed, Material Removal Rate. These parameters will be analysed using Taguchi Parameter Design with different input process parameters. Also, different process parameters attaining higher machining efficiency by acquiring a higher cutting speed, Material Removal Rate and low surface roughness.

\section{References}

[1] Aditya Modgil (2003). Effects of high speed machining on surface topography of Titanium alloy (TI6AL4V. University of Florida.

[2] Aniza Aliasa, Bulan Abdullaha, Norliana Mohd Abbasa (2012). Influence of machine feed rate in machining titanium TI-6AL-4V using brass wire and constant current (4A). International Symposium on Robotics and Intelligent Sensors.

[3] Goswami Amitesh, Kumar Jatinder (2012). An investigation into the machining characteristics of Nimonic 80A using CNC WIRE-EDM. International Journal of Advanced Engineering Technology E-ISSN 0976.

[4] Liao, Y. S, Cheng, M. P, Liao, K.W. (2009). An on-line pulse trains analysis system of the wireEDM process. Journal of Materials Processing Technology, 209 4417-4422.

[5] Menzies, Koshy, P. (2008). Assessment of abrasion-assisted material removal in WEDM. CIRP Annals - Manufacturing Technology 57 195-198.

[6] Mohd Ahadlin Mohd Daud, Mohd Zaidi Omar, Junaidi Syarif Zainuddin Sajuri (2004). Effect of WIRE-EDM cutting on fatigue strength of
Volume 02 Issue 06 June 2020

AZ61 Magnesium alloy. Journal Mekanikal, No.30, 68-76.

[7] Muthu Kumar, V.A. Suresh Babu, A.B. Venkatasamy, R.C. and Raajenthiren, M. (2010). Optimization of the WEDM Parameters on Machining Incoloy800 Super alloy withMultiple Quality. Characteristics International Journal of Engineering Science and Technology, Vol.2(6),1538-1547.

[8] Neeraj Sharma, Rajesh Khanna (2010). Optimization of process parameters of cryogenic treated D-3 in WEDM by Taguchi Approach. International Journal of Engineering Research and Applications (IJERA) Vol. 1, Issue 3, pp.546-553.

[9] Olofson, C.T. Boulger, F.W. Gurklis, J.A. (1965). Machining and grinding of titanium and its alloy. Nasa technical nas4 tm x-53312 memorandum.

[10] Rohit Garg (2010). Effect of process parameters on performance measures of wire electrical discharge machining. Ph.D. Thesis National Institute of Technology, Kurukshetra-136 119, Haryana, India.

[11] Sarkar, S. Sekh, M. Mitra, S. Bhattacharyya, B. (2008). Modeling and optimization of wire electrical discharge machining of TiAl in trim cutting operation. Journal of materials processing technology 205 376-387.

[12] Shajan Kuriakose, Shunmugam, M.S. (2004). Characteristics of wire-electro discharge machined Ti6A14V surface. Materials Letters, 2231-2237.

[13] Scott, F. Miller, Albert, J. Shih, Jun Qub (2004). Investigation of the spark cycle on material removal rate in wire electrical discharge machining of advanced materials. International Journal of Machine Tools\& Manufacture 44.

[14] Singh, H. Garg, R. (2009). Effects of process parameterson material removal rate in WEDM. Journal of Achievement in Material and Manufacturing Engineering, Volume-32.

[15] Vamsi Krishna Pasam, Surendra Babu Battula, Madar Valli P, Swapna (2004). Optimizing surface finish in WIER -EDM using the Taguchi parameter design method. GITAM University. 